\title{
Contrasting responses of terrestrial ecosystem production to hot temperature extreme regimes between grassland and forest
}

\author{
Y. Zhang ${ }^{1}$, M. Voigt ${ }^{1}$, and H. Liu ${ }^{2}$ \\ ${ }^{1}$ Institute for Space Sciences, Freie Universität Berlin, 12165 Berlin, Germany \\ ${ }^{2}$ Changjiang River Scientific Research institute, Changjiang Water Resources Commission, 430010 Wuhan, China \\ Correspondence to: Y. Zhang (yongguang.zhang@wew.fu-berlin.de)
}

Received: 7 March 2014 - Published in Biogeosciences Discuss.: 28 April 2014

Revised: 12 November 2014 - Accepted: 2 December 2014 - Published: 29 January 2015

\begin{abstract}
During the past several decades, observational data have shown a faster increase in hot temperature extremes than the change in mean temperature. Increasingly high extreme temperatures are expected to affect terrestrial ecosystem function. The ecological impact of hot extremes on vegetation production, however, remains uncertain across biomes in natural climatic conditions. In this study, we investigated the effects of hot temperature extremes on vegetation production by combining the MODIS enhanced vegetation index (EVI) data set and in situ climatic records during the period 2000 to 2009 from 12 long-term experimental sites across biomes and climate. Our results show that higher mean annual maximum temperatures $\left(T_{\max }\right)$ greatly reduced grassland production, and yet enhanced forest production after removing the effect of precipitation. The relative decrease in vegetation production was $16 \%$ for arid grassland and $7 \%$ for mesic grassland, and the increase was $5 \%$ for forest. We also observed a significantly positive relationship between interannual aboveground net primary production (ANPP) and $T_{\max }$ for the forest biome $\left(R^{2}=0.79\right.$, $P<0.001)$. This line of evidence suggests that hot temperature extremes lead to contrasting ecosystem-level responses of vegetation production between grassland and forest biomes. Given that many terrestrial ecosystem models use average daily temperature as input, predictions of ecosystem production should consider such contrasting responses to increasingly hot temperature extreme regimes associated with climate change.
\end{abstract}

\section{Introduction}

The observed global temperature showed a warming of $0.85^{\circ} \mathrm{C}\left(0.65\right.$ to $\left.1.06^{\circ} \mathrm{C}\right)$ over the period of 1880 to 2012 , and the number of warm days and nights has increased at the global scale (IPCC, 2013). Future temperature is expected to continue to warm more rapidly over land than ocean, and there will be more frequent hot and fewer cold temperature extremes over most land area (IPCC, 2013). Terrestrial ecosystems are strongly impacted by climate and climate change (Nemani et al., 2003), and hence this trend towards hot temperature extremes would have important consequences on terrestrial ecosystems (IPCC, 2012). Numerous modeling and observational climate warming studies have shown the general enhancement of vegetation growth or increases in vegetation greenness in northern terrestrial ecosystems (e.g., Keeling, et al., 1996; Myneni, et al., 1997; Zhou et al., 2001; Neigh et al, 2008; Wu et al., 2011). However, knowing the general response of ecosystems tells us little about how the ecosystem in a particular location will respond or how different ecosystem responds to hot temperature extremes. For example, Peng et al. (2013) recently reported that the growing-season greenness was positively correlated with the maximum daily temperature $\left(T_{\max }\right)$ in northwestern North America and Siberia but negatively correlated in drier temperate regions such as western China, central Eurasia, and central and southwestern North America.

Usually, field manipulated experiments have been conducted to investigate the effects of climatic warming on ecosystem (Alward et al., 1999; Shaver et al., 2000; Wu et al., 2011). Such experimental manipulations are important to understand and quantify the individual contribution of climatic 
Table 1. Descriptions of the sites in this study ${ }^{\mathrm{a}}$.

\begin{tabular}{|c|c|c|c|c|c|c|}
\hline Site and location & $\begin{array}{l}\text { Latitude } \\
\text { (degree) }\end{array}$ & $\begin{array}{l}\text { Longitude } \\
\text { (degree) }\end{array}$ & Land cover & $\begin{array}{l}\text { MAP } \\
(\mathrm{mm})^{\mathrm{b}}\end{array}$ & $\begin{array}{l}\text { Max. temp- } \\
\text { erature }\left({ }^{\circ} \mathrm{C}\right)\end{array}$ & Code \\
\hline Desert Exp. Range, UT & 38.547 & -113.712 & Arid grassland & $216(65)$ & $19(1.1)$ & $\mathrm{DE}$ \\
\hline Jornada Exp. Range, NM & 32.589 & -106.844 & Arid grassland & $242(78)$ & $25(0.7)$ & $\mathrm{JE}$ \\
\hline Walnut Gulch Exp. Watershed, AZ & 31.736 & -109.938 & Arid grassland & $311(85)$ & $25(1.0)$ & WG \\
\hline Santa Rita Exp. Range, AZ & 31.846 & -110.839 & Arid grassland & 447 (129) & $29(0.7)$ & SR \\
\hline Central Plains Exp. Range, CO & 40.819 & -104.748 & Arid grassland & $381(91)$ & $16(1.4)$ & $\mathrm{CP}$ \\
\hline Southern Plains Exp. Range, OK & 36.614 & -99.576 & Mesic grassland & $586(153)$ & $22(0.9)$ & SP \\
\hline Little Washita Creek, OK & 34.918 & -97.956 & Mesic grassland & $796(195)$ & $24(1.2)$ & LW \\
\hline Little River Watershed, GA & 31.537 & -83.626 & Temperate conifer forest & $1148(257)$ & $25(0.6)$ & LR \\
\hline Mahatango Creek, PA & 40.731 & -76.592 & Temperate broadleaf forest & $1058(179)$ & $16(0.9)$ & MC \\
\hline Cutfoot Experimental Forest, MN & 47.4264 & -94.0141 & Temperate broadleaf forest & $665(101)$ & $11(1.1)$ & $\mathrm{CF}$ \\
\hline Bent Creek Exp. Forest, NC & 35.500 & -82.624 & Temperate mixed forest & $1227(239)$ & $19(0.6)$ & $\mathrm{BC}$ \\
\hline Caspar Creek, CA & 39.337 & -123.748 & Mediterranean forest & $1054(301)$ & $16(0.7)$ & $\mathrm{CC}$ \\
\hline
\end{tabular}

aPrecipitation and temperature for the 40-year period 1970-2009 were available for all sites except JE, for which data were available for a 32-year period 1978-2009.

${ }^{\mathrm{b}}$ Average annual sum of precipitation (MAP) and average annual mean max temperature with standard deviation in parentheses.

warming on vegetation growth by controlling other global change factors. However, these studies have usually been conducted either on an individual ecosystem or over shortterm periods, which render the comparisons across biomes that may differ between regions and ecosystem difficult. A main problem with these experiments is that they do not incorporate the entire micro- and macro-environmental aspects of variable weather. In addition, the long-term responses of ecosystem function are difficult to capture in warming experiments most of which were short term $(<5$ years) (Wu et al., 2011). In other words, manipulated experiments are spatially and temporally restricted. The results from these manipulated studies are needed to understand in the context of long-term experiments in the natural field settings. An alternative to manipulated experiments is to analyze these effects on ecosystem processes in natural field settings with longterm measurements across biomes (Huxman et al., 2004).

Although individual grassland or forest sites have been conducted for their response to climatic warming or extremes (Wu et al., 2011; Smith, 2011), there is still no consensus on how ecosystem production will respond to temperature extremes across biomes from arid grassland to forest. Furthermore,many comparison studies used ecosystem production from a compilation of in situ measurements from long-term experimental sites (Huxman et al., 2004). However, the measuring procedures of vegetation production are not consistent across sites, and in some cases, not consistent over time at a given site (Sala et al., 1988), and this will result in some uncertainties. As a result, we are lacking generalizations about the regional behavior of terrestrial ecosystem with more hot temperature extreme regimes.

The last decade has witnessed dramatic global warming: 9 of the 10 warmest years on record have occurred during the 21st century (NOAA, 2013). These conditions are similar to those expected due to climate change (IPCC, 2013). In par- ticular, the United States has warmed faster than the global rate since the late 1970s, and heat waves in 2005, 2006, and 2007 broke all-time records for high maximum and minimum temperatures (NOAA, 2013). Therefore, this recent climatic condition provides an opportunity to study the functional response of biomes to hot temperature extremes with respect to future climate change.

In this study, we used a 10-year data set of MODerate resolution Imaging Spectroradiometer (MODIS) enhanced vegetation index (EVI) (Huete et al., 2002) as an indicator of aboveground net primary production (ANPP), in combination with field observations from 12 long-term experimental sites in the conterminous United States. The primary objective of this study was to examine the response of vegetation production to hot temperature extremes, with particular focus on quantifying the direction and magnitude of ANPP long-term response across biomes from semi-arid grassland to temperate forest. We first assessed the changes in annual ANPP due to higher temperature extremes across biomes. Then, we examined the link between temperature extremes and annual ANPP after controlling the effects of precipitation and low temperature.

\section{Materials and methods}

\subsection{Study sites and meteorological data}

Twelve USDA experimental sites across the conterminous United States were used. These sites included different precipitation regimes and biomes representative of ecosystems ranging from arid grassland to temperate forest. They represent a broad range of production, climatic and soil conditions, and life history characteristics of the dominant species. At each site, a location was selected in an undisturbed vegetated area of at least $2.25 \mathrm{~km} \times 2.25 \mathrm{~km}$ in size (Table 1 ). 


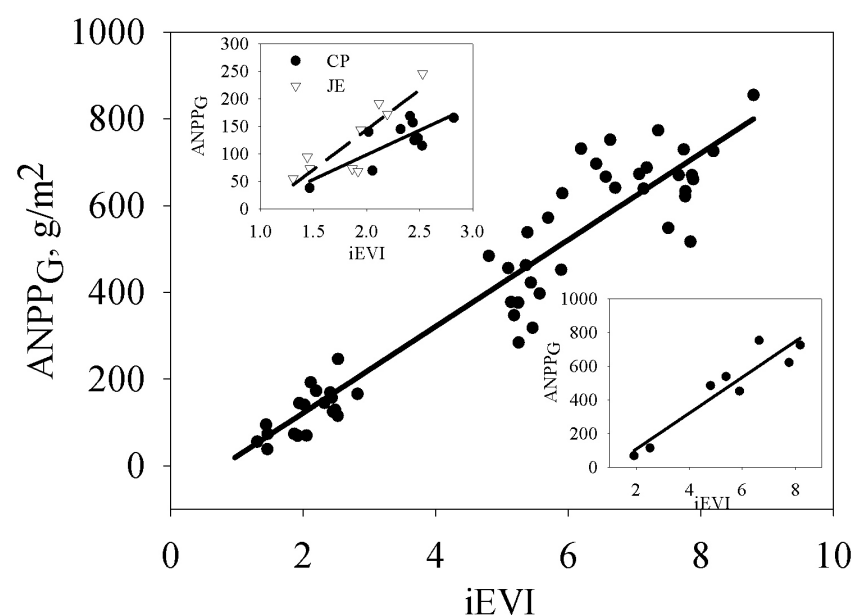

Figure 1. Relationship between annual ground measurements of $\operatorname{ANPP}\left(\mathrm{ANPP}_{\mathrm{G}}\right)$ and the corresponding iEVI derived from MODIS data during the period between 2000 and 2009 for nine selected sites across biomes $\left(R^{2}=0.90, P<0.0001\right.$; Table 2$)$. The upper inset shows the relationship at two sites of CP and JE $\left(R^{2}=0.63\right.$ and 0.74 , respectively, $P<0.01$ ). The lower inset shows the relationship between ANPP $_{\mathrm{G}}$ and $\mathrm{iEVI}$ for the year 2001 across the 9 sites $\left(R^{2}=0.88, P<0.001\right)$.

According to Köppen-Geiger climate classification (Peel et al., 2007), arid grassland (DE, JE, WG, and SR) and Mediterranean forest (CC) sites experience a climate with a dry season and are seasonally water-limited, whereas mesic grassland (CP, SP, and $\mathrm{LW}$ ) and temperate forest (LR, MC, $\mathrm{BC}$, and $\mathrm{CF}$ ) sites experience humid climate and can be temperature-limited.

The climate data set used in this study was from in situ daily precipitation and maximum and minimum air temperature measured at the local weather station representative of each site from 1970 to 2009 except for JE, for which data were available from 1978 to 2009. Long-term (40-year) in situ temperature data sets were used to identify climate extremes within the past decade. In this study, we considered two extreme temperature indices. Maximum temperature in$\operatorname{dex}\left(T_{\max }\right)$ represents annual mean daily maximum temperature, and minimum temperature index $\left(T_{\min }\right)$ represents annual mean daily minimum temperature. Annual values were based on the hydrologic year extending from 1 October to 30 September. The interannual variability of temperature extremes was represented by the anomaly, which was calculated as the departure of a given year from the mean of the period between 1970 and 2009 divided by the standard deviation. Positive anomaly means higher $T_{\max }$ above the longterm average, and vice versa for negative anomaly.

\subsection{Satellite data}

We used satellite observations of the EVI from the MODIS as a proxy for annual ANPP. The EVI data set was derived from the MODIS land product subset (MOD13Q1) with 16-day and $250 \mathrm{~m}$ resolutions for the period of 2000-2009. To compare EVI with in situ climatic measurements, we averaged the EVI data over an area of $\sim 2.25 \mathrm{~km} \times 2.25 \mathrm{~km}(9 \times 9$ pixels) based on the coordinates for each site in Table 1 . A total of 230 scenes ( 23 scenes $\times 10$ years) was obtained for each of the 12 sites. In order to eliminate the noise of low-quality, cloud- and aerosol-contaminated pixels, a pixelbased quality assurance (QA) control was applied to generate a less noisy time series data set based on the quality flag in MOD13Q1 product (Ponce-Campos et al., 2013). Then the software TIMESAT was used to smooth the QA-filtered time series of EVI as well as to estimate the vegetation parameters such as EVI integrals of the growing season (Jönsson and Eklundlh, 2004). The large integral of MODIS EVI measurements (referred to as iEVI hereafter) over the whole year was used as our surrogate measure of ANPP (Fig. 1). The MODIS iEVI has been used to quantify the dynamics of ANPP across biomes ranging from arid grassland to forest (Zhang et al., 2013; Ponce-Campos et al., 2013). For this study, to validate the relation between iEVI and annual ANPP for the data set in this study, ground measurements of ANPP $\left(\mathrm{ANPP}_{\mathrm{G}}\right)$ during the period 2000-2009 were compiled for nine sites (53 years in total) across the United States (Table 2). A strong relationship (Eq. 1) between $\mathrm{ANPP}_{\mathrm{G}}$ and the corresponding iEVI was derived across biomes for these long-term experimental sites (Fig. 1):

$$
\begin{aligned}
& \mathrm{ANPP}_{\mathrm{G}}=100.97 \times \mathrm{iEVI}-85.28 \\
& R^{2}=0.90 \quad P<0.001 \quad(n=53) .
\end{aligned}
$$

It should be noted that Eq. (1) is a spatiotemporal relationship between $\mathrm{ANPP}_{\mathrm{G}}$ and $\mathrm{iEVI}$ across biomes. At the site scale, the temporal relationship between $\mathrm{ANPP}_{\mathrm{G}}$ and iEVI is not as strong as Eq. (1), but the site-specific comparison with $\mathrm{ANPP}_{\mathrm{G}}$ from the plot-scale ground measurements at two sites in Table 1 (CP and JN) showed generally good agreement during the period between 2000 and 2009 (Fig. 1 inset, $R^{2}=0.70, P<0.01$ ) in spite of the scale differences between measurements of iEVI and $\mathrm{ANPP}_{\mathrm{G}}$. Hence iEVI could show the interannual variability of vegetation growth. On the other hand, the spatial correlation is also significantly positive between $\mathrm{ANPP}_{\mathrm{G}}$ and the corresponding iEVI, as shown in Fig. 1 (inset) for the year of 2001 across biomes $\left(R^{2}=0.88, P<0.001\right)$. Therefore, we assumed that the iEVI can be a reasonable surrogate for ANPP interannual variability and provide consistent sensitivity across biomes ranging from arid grassland to forest in our analyses.

\subsection{Data analysis}

To investigate the sensitivity of ANPP to temperature extreme $\left(T_{\max }\right)$ across biomes, we compared the iEVI measured during years with extremely high temperatures with the mean iEVI of all other years during 2000-2009 for each site. Years 
Table 2. Sites with "in-situ" ANPP measurements within the period of 2000-2009 for validation with iEVI.

\begin{tabular}{|c|c|c|c|}
\hline Site & Biome and Location & Period & Source \\
\hline Jornada LTER & Arid grassland, New Mexico & $2000-2009$ & http://www.lternet.edu/sites/ \\
\hline Sevilleta LTER & Arid grassland, New Mexico & $2002-2003$ & http://www.lternet.edu/sites/ \\
\hline Shortgrass Steppe LTER & Grassland, Colorado & 2000-2009 & http://www.lternet.edu/sites/ \\
\hline Cedar Creek LTER & Grassland, Minnesota & 2000-2007 & http://www.lternet.edu/sites/ \\
\hline Konza Prairie LTER & Grassland, Kansas & 2000-2002 & http://www.lternet.edu/sites/ \\
\hline Harvard Forest & Mixed forest, Massachusetts & 2000-2006 & http://www.lternet.edu/sites/ \\
\hline Metolius Intermediate Pine & Evergreen needleleaf forest, Oregon & 2001 & http://public.ornl.gov/ameriflux/ \\
\hline Park Falls & Deciduous broadleaf forest, Wisconsin & 2000, 2004 & http://public.ornl.gov/ameriflux/ \\
\hline Ohio Hills FFs & Mixed forest, Ohio & 2001-2002 & Chiang et al. (2008) \\
\hline University of Michigan Biological Station & Deciduous broadleaf forest, Michigan & 2000-2006 & Gough et al. (2008) \\
\hline
\end{tabular}

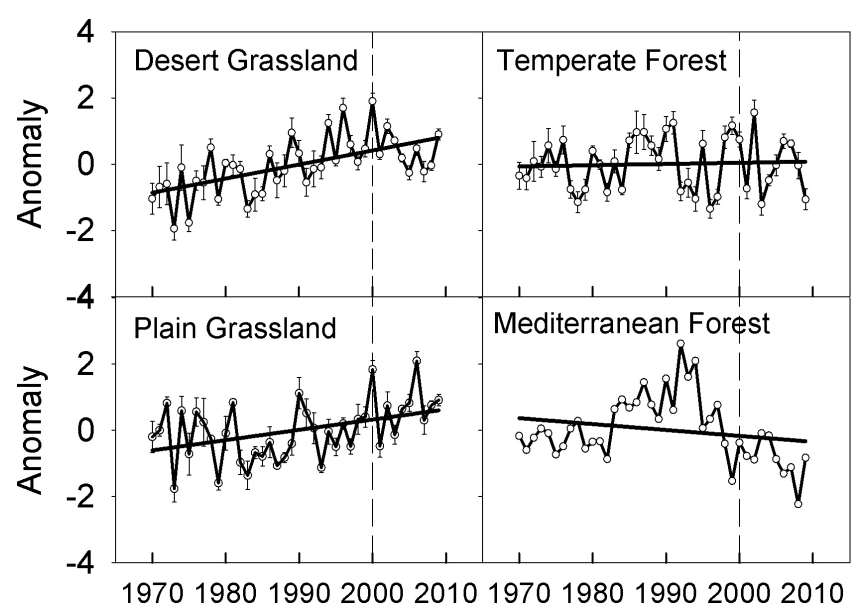

Figure 2. Long-term trends of the anomaly of $T_{\max }$ during 1970 2009 for different biome types. DG, arid grassland sites (DE, JE, WG, SR, and CP in Table 1); MG, mesic grassland sites (SP and $\mathrm{LW}$ in Table 1); TF, temperate forested sites (LR, MC, BC, and CF in Table 1); MF, Mediterranean forested site (CC). The dotted line shows the year of 2000 for the starting year of the MODIS EVI data set.

with extremely high temperatures were defined as those for which the $T_{\max }$ anomaly was $\geq 1$ or the maximum anomaly year when there is no anomaly $>1$ during 2000-2009. Since both precipitation and temperature $\left(T_{\max }\right.$ and $\left.T_{\min }\right)$ have limitations on vegetation production (iEVI) and they covary with one another, we also used partial correlation analysis to assess the relationship between $\mathrm{iEVI}$ and $T_{\max }$ by removing the effects of precipitation and $T_{\min }$. Partial correlation analysis is widely used to isolate the relationship between two variables by removing the effects of many correlated variables. A Duncan multiple range test was used to determine significant differences in temperature and iEVI among groups.

\section{Results and discussion}

\subsection{Long-term trends of the anomaly of $T_{\max }$}

Figure 2 shows the long-term trends of $T_{\max }$ for the four biome types (Table 1). For desert grassland, annual mean maximum temperature increased by $1.66^{\circ} \mathrm{C}(P<0.0001)$ during the 40-year period from 1970 and 2009 (Fig. 2). For mesic grassland, $T_{\max }$ increased by $1.21^{\circ} \mathrm{C}(P<0.0001)$ during 1970-2009 (Fig. 2). There was no significant trend for $T_{\max }$ for temperate forest sites. In contrast, $T_{\max }$ decreased slightly for Mediterranean forest even though not statistically significant for the whole 40-year period (Fig. 2, $P>0.1)$. However, Fig. 2 shows that there were two different periods for $T_{\max }$ at the Mediterranean forest site (CC in Table 1). $T_{\max }$ increased by $1.86^{\circ} \mathrm{C}(P<0.0001)$ before the earlier $1990 \mathrm{~s}$ but then dropped dramatically by $-3.46^{\circ} \mathrm{C}$ $(P<0.0001)$ after 1992 (Fig. 2). The temperature rises observed in desert and mesic grassland are consistent with the observation in the southwestern US and the Great Plains (USGCRP, 2009; MacDonald, 2010). However, the unchanged annual mean $T_{\max }$ in the temperate forest sites is not consistent with the regional temperature rise in the eastern US (USGCRP, 2009).

\subsection{Contrasting responses to $T_{\max }$ between grassland and forest biomes}

Figure 3 shows that annual iEVI was significantly correlated with $T_{\max }\left(R^{2}=0.79, P<0.001\right)$ across the temperature gradient of forested sites, and a stronger relation was identified between the decadal maximum $T_{\max }$ and corresponding iEVI ( $R^{2}=0.95, P<0.005$; Fig. 3$)$. Because the slopes of these two relations are not significantly different $(F$ test, $P>0.05$; Fig. 3), this confirms that forest production increases with elevated temperature across the temperature gradient (Magnani et al., 2001; Wullschleger et al., 2003; Huxman et al., 2004). This also suggests that the decadal maximum $T_{\max }$ may not affect the overall sensitivity of interannual ANPP to mean annual temperature. Figure 3 also 


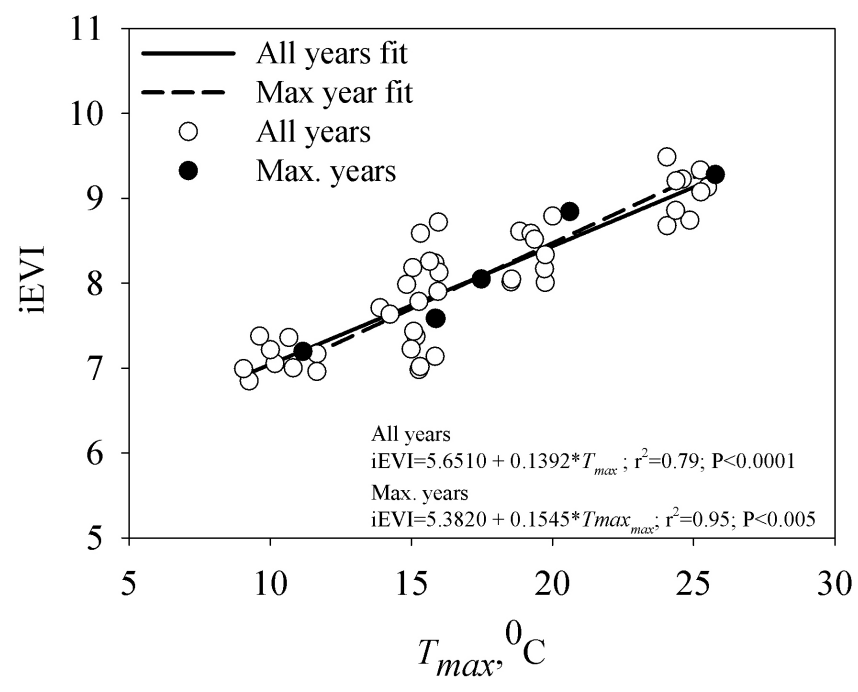

Figure 3. Relationship between iEVI and $T_{\max }$ and their maximumyear $T_{\max }-\mathrm{iEVI}$ relationship for five forested sites. The dotted line shows the linear relationship between maximum-year $T_{\max }$ and the relevant iEVI for all the sites.

suggests that maximum temperature can explain $80 \%$ of the variability of vegetation production across these forest sites. For the grassland sites, however, there is no significant correlation between mean annual $\mathrm{iEVI}$ and $T_{\max }\left(R^{2}=0.05\right.$, $P=0.64)$. This is consistent with the fact that vegetation production is more controlled by water availability for grasslands in arid and semi-arid regions and interannual ANPP being related to soil moisture variability (Knapp and Smith, 2001; Knapp et al., 2002; Cherwin and Knapp, 2012). On the other hand, the forest biome is more temperature-limited with regard to productivity, particularly in regions that are not constrained by water, and climatic warming can stimulate vegetation growth through enhancing summer photosynthesis (Churkina and Running, 1998; Nemani et al., 2003; Piao et al., 2007).

Within sites, however, the interannual iEVI was not correlated with interannual variations in $T_{\max }$ at any forest site $(P>0.05)$. The differences between spatial and temporal patterns of forest ANPP responses to $T_{\max }$ reflect different underlying mechanisms at regional and local scale. The regional pattern of forest ANPP is determined primarily by temperature, while the temporal pattern for a given ecosystem is most likely affected by interactions between temperature and nutrient availability. Several studies have found limited forest production response to warming alone but significant response to warming with fertilization (Parsons et al., 1994; Press et al., 1998; Rustad et al. 2001; Strömgren and Linder 2002; Xu et al. 2011).

Among biomes, higher $T_{\max }$ with an anomaly $>1$ had a direct negative effect on vegetation production in grassland ecosystems, especially for arid grassland, but a positive effect on forest ecosystems (Fig. $4, P<0.05$ ). On average, the de-

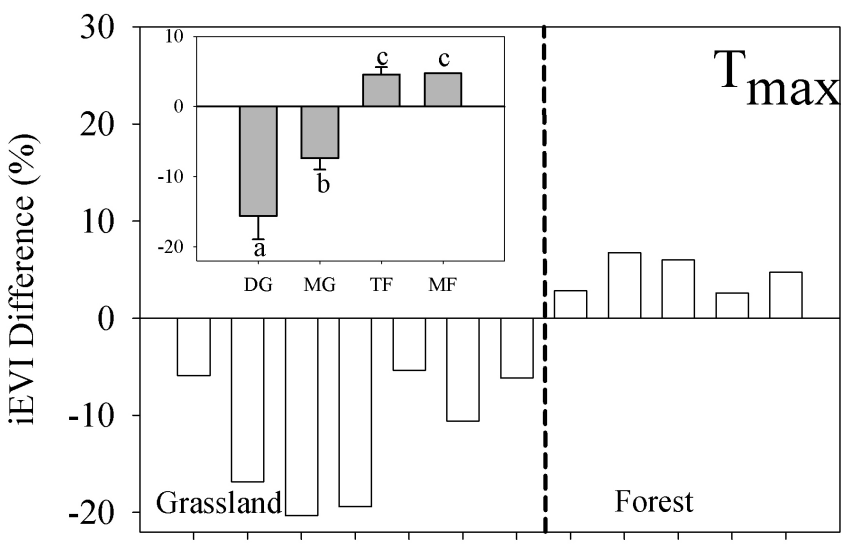

DE JE WGSR CP SPLWLRMCBC CF CC

Site

Figure 4. Comparison of iEVI differences between the extreme years and average of all other years of $T_{\max }$ across sites. Extreme years mean that the years of $T_{\max }$ anomaly are $\geq 1$. The inset denotes the average differences by biome type. DG, arid grassland sites (DE, JE, WG, and SR in Table 1); MG, mesic grassland sites (CP, SP, and LW in Table 1); TF, temperate forested sites (LR, MC, $\mathrm{BC}$, and CF in Table 1); MF, Mediterranean forested site (CC). Different letters indicate significant differences at $P<0.05$.

creases in iEVI were up to $7 \%$ for mesic grassland, and $16 \%$ for arid grassland (Fig. 4, inset). This may be attributed to the negative effects of warming temperatures on water availability through enhanced evapotranspiration (Seager and Vecchi, 2010). In contrast, higher $T_{\max }$ enhanced mean annual iEVI by $5 \%$ for both temperate and Mediterranean forest sites (Fig. 4). There were larger, positive responses of ANPP to higher temperatures for forested sites in colder environments, which are the sites of BC and MC (Fig. 4).

The results stated above demonstrate the effects of hot temperature extreme on vegetation production without considering the confounding effects of other variables such as precipitation and $T_{\min }$. There is a highly positive correlation between $T_{\max }$ and $T_{\min }$. To isolate the role of $T_{\max }$ from precipitation and $T_{\min }$, we alternately investigated the apparent responses of iEVI to $T_{\max }$ with partial correlation analyses to remove the confounding effects. Figure 5 shows how interannual iEVIs respond to variations in interannual $T_{\max }$ across sites. After removing the effects of $T_{\min }$ and precipitation in the partial correlation analyses, the individual $T_{\max }$ interannual changes again show the contrasting effects on the interannual iEVI between grassland and forest sites (Fig. 5). For desert grassland sites, interannual iEVI is negatively correlated with interannual $T_{\max }$ with statistical significance at the 0.05 level $(R=0.35)$. There is no significantly partial correlation between $T_{\max }$ and annual iEVI for mesic grassland sites (Fig. 5), implying little or no response of ecosystem production to $T_{\max }$ after removing the effects of $T_{\min }$ and precipitation. In contrast, interannual 


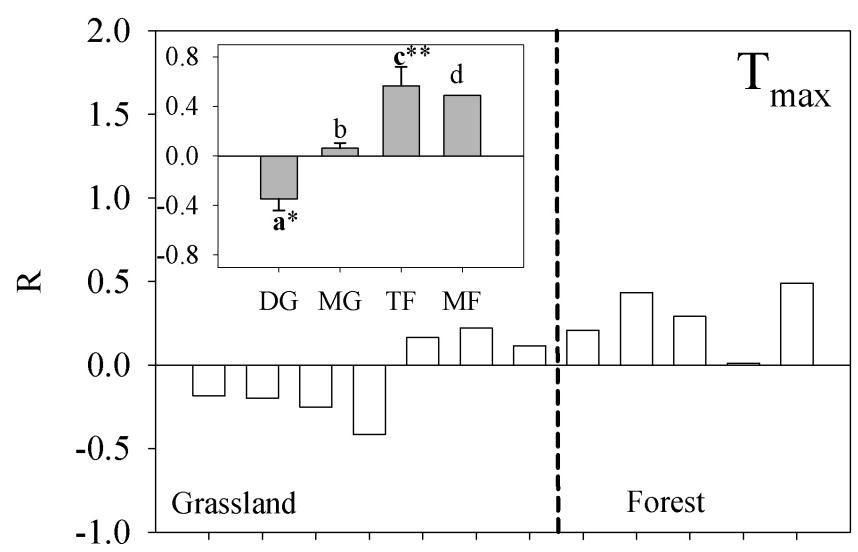

DE JE WGSR CP SP LWLRMCBC CF CC

Site

Figure 5. Partial correlations between iEVI and $T_{\max }$ after controlling the effects of $T_{\min }$ and precipitation across sites. (1) Statistically significant at the $95 \%(P<0.05)$ level; $(2)$ statistically significant at the $99.9 \%(P<0.001)$ level.

$T_{\max }$ variations exhibit significantly positive partial correlations with interannual iEVI changes for temperate forest sites $(R=0.57 ; P<0.001)$. For the Mediterranean forest site of Caspar Creek, it also shows positive partial correlations between interannual $T_{\max }$ and iEVI but without statistical significance $(R=0.49 ; P=0.22)$ due to fewer data sets from only site. This opposite response of interannual iEVI to $T_{\max }$ between wet and dry temperate regions of the North America agrees well with a recent global study by Peng et al., 2013, in which remarkable spatial patterns of the partial correlations between growing-season greenness and $T_{\max }$ over the Northern Hemisphere were shown.

In all, the two approaches in the present study suggest that hot temperature extremes imposed a negative effect on vegetation production for grassland, especially desert grassland in the southwestern US, while it has a positive effect on forest (Figs. 4 and 5). This difference in response between grassland versus forest may be related to the adaptations of dominant species in terms of their response to warming temperature. Higher $T_{\max }$ and warming climate would imply drier soils through increased evaporative demand (Manabe and Wetherald, 1986) and decreased production due to decreases in stomatal conductivity, down-regulation of the photosynthetic processes, and increased allocation to roots in arid and semi-arid regions (Chaves et al., 2002). Our results agree well with the results of previous studies (Braswell et al., 1997; Piao et al., 2006; Munson et al., 2012) that higher temperatures may have directly negative effects on vegetation growth in arid and semi-arid grassland. With more atmospheric carbon dioxide in the future, however, such warming desiccation effects would be likely modified at least for arid grasslands as shown by Morgan et al. (2011). For forest, the positive effect is consistent with the results reported by
Rustad et al. (2001) and McMahon et al. (2010) for ANPP in ecosystem warming experiments that higher $T_{\max }$ would have a positive impact on forest production (Boisvenue and Running, 2006). Previous studies have also shown that higher temperatures favor tree growth by enhancing photosynthesis (Lukac et al., 2010) and nutrient uptake (Weih and Karlsson, 2002), especially in sites where trees were not typically constrained by moisture stress. Thus, these contrasting responses to $T_{\max }$ in different ecosystems could have different effects on regional vegetation carbon uptake (Braswell et al., 1997). However, it should be noted that, due to data limitations, only 12 sites were used in this study. We need more data from all terrestrial ecosystems to test whether the contrasting effect of temperature extremes is a general behavior in forest and grassland ecosystems. Furthermore, the results reported here may be temporal, and the long-term impact of temperature extremes on ecosystem functional integrity across biomes is yet unknown. The ongoing field measurements of carbon flux and meteorological data from eddy covariance flux method for different ecosystem may provide an opportunity to validate the assumption in this study.

\section{Conclusions}

Understanding how vegetation production responds to extreme warm temperature regimes is crucial for assessing the impacts of climate change on terrestrial ecosystem. Recent record-breaking high temperatures in the contiguous US provide the opportunity to study such effects. Our study offers a generalization of the functional response of ecosystem to hot extreme conditions predicted with climate change across biomes in the natural climatic conditions. By using satellite and in situ meteorological data, we found a contrasting response of terrestrial ecosystem to extreme warm temperature anomalies between grassland and forest biomes in natural settings. The opposite direction and magnitude of response indicates different sensitivities across ecosystems to hot temperature extremes. A recent study has shown that there is a continuous increase in hot extremes over land, despite the slowed rate of increase in annual global mean temperature (Seneviratne et al., 2014). Hence, the sensitivity of ecosystem production in response to hot extremes across biomes found here has important implications. Current terrestrial ecosystem models usually utilize daily mean or monthly temperature data as input, and hence they may neglect the response of vegetation to extreme warm temperature $\left(T_{\max }\right)$. To some extent, the effects of hot extremes are more relevant for climate change impacts than global mean temperature on ecosystems (IPCC, 2012, 2013). Hence, this work further strengthens our understandings of the ecosystemlevel response to extreme warm temperatures across biomes. This study also clarifies the value of long-term experimental sites together with continuing satellite-based observations such as EVI in future studies. This compelling result in a 
natural setting at the ecosystem level should play a role in future climate change impact studies.

Acknowledgements. The work by Y. Zhang and M. Voigt was funded by the Emmy Noether Programme (GlobFluo project) of the German Research Foundation. Thanks to M. Susan Moran, Anthony R. Buda, David D. Bosch, Stacey A. Gunter, Stanley G. Kitchen, W. Henry McNab, Jack A. Morgan, Mitchel P. McClaran, Diane S. Montoya, Debra P. C. Peters, and Patrick J. Starks for providing the climatic data. We are also grateful for access to multi-site, long-term data provided through the EcoTrends Project (www.ecotrends.info). This work used biological data acquired by the LTER network. We acknowledge the Oak Ridge National Laboratory (ORNL) Distributed Active Archive Center (DAAC) for making these data available. We thank Bai Yang, Jyh-Min Chiang, Beverly Law, and Arlyn Andrews for providing suggestions about the ANPP data. We also thank the principal investigators, information managers, scientists, and technicians responsible for measuring ANPP at the LTER sites. The authors also gratefully acknowledge the valuable suggestions made by Christopher Kyba at the Freie Universität Berlin. The authors are also are grateful to the three anonymous reviewers for their valuable comments.

Edited by: E. Pendall

\section{References}

Alward, R. D., Detling, J. K., and Milchunas, D. G.: Grassland vegetation changes and nocturnal global warming, Science, 283, 229-231, 1999.

Braswell, B. H., Schimel, D. S., Linder, E., Moore, B.: The response of global terrestrial ecosystems to interannual temperature variability, Science, 238, 870-872, 1997.

Boisvennue, C. and Running, S. W.: Impacts of climate change on natural forest production- evidence since the middle of the 20th century, Glob. Change Biol., 12, 862-882, 2006.

Chaves, M. M., Pereira, J. S., Maroco, J. P.: How plants cope with water stress in the field: photosynthesis and growth, Ann. Bot., 89, 907-916, 2002.

Cherwin, K. and Knapp, A. K.: Unexpected patterns of sensitivity to drought in three semi-arid grasslands, Oecologia, 169, 845-852, 2012.

Chiang, J. M., McEwan, R. W., Yaussy, D. A., and Brown, K. J.: The effects of prescribed fire and silvicultural thinning on the aboveground carbon stocks and net preimary production of overstory trees in an oak-hickory ecosystem in southern Ohio, Forest. Ecol. Manage., 255, 1584-1594, 2008.

Churkina, G. and Running, S. W.: Contrasting climate controls on the estimated production of global terrestrial biomes. Ecosystems, 1 pp., 206-215, 1998

Gough, C. M., Vogel, C. S., Schmid, H. P., Su, H. B., and Curtis, P. S.: Multi-year convergence of biometric and meteorological estimates of forest carbon storage, Agr. Forest. Meteorol., 148, 158-170, 2008

Huete, A. R., Didan, K., Miura, T., Rodriguez, E. P., Gao, X., and Ferreira, L. G.: Overview of the radiometric and biophysical per- formance of the MODIS vegetation indices, Remote Sens. Environ., 83, 195-213, 2002.

Huxman, T. E., Smith, M. D., Fay, P. A., Knapp, A. K., Shaw, M. R., Loik, M. E., Smith, S. D., Tissue, D. T., Zak, J. C., Weltzin, J. F., Pockman, W. T., Sala, O. E., Haddad, B. M., Harte, J., Koch, G. W., Schwinning, S., Small, E. E., and Williams D. G.: Convergence across biomes to a common rain-use efficiency, Nature, 429, 651-654, 2004.

IPCC: Managing the Risks of Extreme Events and Disasters to Advance Climate Change Adaptation, in: A Special Report of Working Groups I and II of the Intergovernmental Panel on Climate Change, edited by: Field, C. et al., Cambridge University Press, Cambridge, UK, and New York, NY, USA, 582 pp., 2012.

IPCC: Climate Change 2013: The Physical Science Basis, in: Contribution of Working Group I to the Fifth Assessment Report of the Intergovernmental Panel on Climate Change, edited by: Stocker, et al., Cambridge University Press, Cambridge, United Kingdom and New York, NY, USA, 1535 pp., 2013.

Jonsson, P. and Eklundh, L.: TIMESAT-a program for analyzing time-series of satellite sensor data, Comput. Geosci., 30, 833845, 2004.

Knapp, A. K. and Smith, M. D.: Variation among biomes in temporal dynamics of aboveground primary production, Science, 291, 481-484, 2001.

Knapp A. K., Fay, P. A., Blair, J. M., Collins, S. L., Smith, M. D., Carlisle, J. D., Harper, C. W., Danner, B. T., Lett, M. S., and McCarron, J. K.: Rainfall variability, carbon cycling, and plant species diversity in a mesic grassland, Science, 298, 2202-2205, 2002.

Keeling, R. F., Piper, S. C., and Heimann, M.: Global and hemispheric $\mathrm{CO} 2$ sinks deduced from changes in atmospheric $\mathrm{O} 2$ concentration., Nature, 381, 218-221, 1996.

Lukac, M., Calfapietra, C., Lagomarsino, A., and Loreto, F.: Global climate change and tree nutrition: effects of elevated $\mathrm{CO}_{2}$ and temperature, Tree Physiology, 30, 1209-1220, 2010

MacDonald, G. M.: Water, climate change, and sustainability in the southwest, Proc. Natl. Acad,Sci. USA, 107, 21256-21262, 2010.

Manabe, S. and Wetherald, R. T.: Reduction in summer soil wetness induced by an increase in atmospheric carbon dioxide, Science, 232, 626-628,1986

McMahon, S. M., Parker, G. G., and Miller, D. R.: Evidence for a recent increase in forest growth, Proc. Natl. Acad. Sci. USA, 107, 3611-3615, 2010.

Myneni, R. B., Keeling, C. D., Tucker, C. J., Asrar, G., and Nemani, R. R.: Increased plant growth in the northern high latitudes from 1981 to 1991, Nature, 386, 698-702, 1997.

Myneni, R. B., Dong, J., Tucker, C. J., Kaufmann, R. K., Kauppi, P. E., Lisk, J., Zhou, L., Alexeyev, V., and Hughes, M. K.: A large carbon sink in the woody biomass of northern forests, Proc. Natl. Acad. Sci. USA, 98, 14784-14789, 2001.

Nemani, R. R., Keeling, C. D., Hashimoto, H., Jolly, W. M., Piper, S. C., Tucker, C. J., Myneni, R. B., and Running, S. W.: Climatedriven increases in global terrestrial net primary production from 1982 to 1999, Science, 300, 1560-1563, 2003.

NOAA National Climatic Data Center, State of the Climate: Global Analysis for Annual 2013, published online December 2013, retrieved on February 21, 2014 from http://www.ncdc.noaa.gov/ sotc/global/2013/13, 2014 
Parsons, A. N., Welker, J. M., Wookey, P. A., Press, M. C., Callaghan, T. V., and Lee, J. A.: Growth responses of four dwarf shrubs to simulated climate change, J. Ecol., 82, 307-318, 1994.

Peel, M. C., Finlayson, B. L., and McMahonl, T. A.: Updated world map of the Köppen-Geiger climate classification, Hydrol. Earth Syst. Sci., 11, 1633-1644, 2007.

Peng, S., Piao, S. L., Ciais, P., Myneni, R., Chen, A., Chevallier, F., Dolman, A. J., Janssens, I.A., Peñuelas, J., Zhang, G., Vicca, S., Wan, S., Wang, S., and Zeng, H.: Asymmetric effects of daytime and night-time warming on Northern Hemisphere vegetation, Nature, 501, 88-92, 2013.

Piao, S. L., Mohammat, A., Fang, J. Y., Cai, Q., and Feng, J. M.: NDVI-based increase in growth of temperate grasslands and its responses to climate change in China, Glob. Environ. Change, 16, 340-348, 2006.

Piao, S. L., Friedlingstein, P., Ciais, P., Viovy, N., and Demarty, J.: Growing season extension and its effects on terrestrial carbon flux over the last two decades, Global Biogeochem. Cy. ,21, GB3018, doi:10.1029/2006GB00288, 2007.

Ponce-Campos, C. G. E., Moran, M. S., Huete, A., Zhang, Y., Bresloff, C., Huxman, T., Bosch, D., McClaran, M. P., Kitchen, S .G., Buda, A., Gunter, S., McNab, H., Peters, D., Starks, P., Montoya, D. S., Heartsill, T., McVicar, T., Eamus, D., and Donohue, R.: Ecosystem resilience despite large-scale altered hydroclimatic conditions, Nature, 494, 349-352, 2013.

Press, M. C., Potter, J. A., Burke, M. J. W., Callaghan, T. V., and Lee, J. A.: Responses of a sub-arctic dwarf shrub community to simulated environmental change, J. Ecol., 86, 315-327, 1998.

Rustad, L. E., Campbell, J. L., Marion, G. M., et al.: A metaanalysis of the response of soil respiration, net nitrogen mineralization, and aboveground plant growth to experimental ecosystem warming, Oecologia, 126, 543-562, 2001.

Sala, O. E., Parton, W. J., Joyce, L. A., and Lauenroth, W. K.: Primary production of the central grassland region of the United States: spatial pattern and major controls, Ecology, 69, 40-45, 1988.

Seager, R., and Vecchi, G. A.: Greenhouse warming and the 21st century hydroclimate of southwestern North America, Proc. Natl. Acad. Sci. USA, 107, 21277-21282, 2010.

Seneviratne, S. I., Donat, M. G., Mueller, B., and Alexander, L. V.: No pause in the increase of hot temperature extremes, Nat. Clim. Change, 4, 161-163, 2014.
Shaver, G. R., Canadell, J., Chapin III, F. S., et al.: Global warming and terrestrial ecosystems: a conceptual framework for analysis, Bioscience, 50, 871-882, 2000.

Smith, M. D.: The ecological role of climate extremes: current understanding and future prospects, J. Ecol., 99, 651-655, 2011.

Strömgren, M. and Linder, S.: Effects of nutrition and soil warming on stemwood production in a boreal Norway spruce stand, Glob. Change Biol., 8, 1195-1204, 2002.

USGCRP: Global Climate Change Impacts in the United States, edited by: Karl, T. R., Melillo, J. M., and Peterson, T. C., United States Global Change Research Program. Cambridge University Press, New York, NY, USA, 2009.

Weih, M. and Karlsson, P. S.: Low winter soil temperature affects summertime nutrient uptake capacity and growth rate of mountain birch seedlings in the subarctic, Swedish lapland,Arctic, Antarctic, and Alpine Res., 34, 434-439, 2002.

Wu, Z., Dijkstra, P., Koch, G. W., Peñuelas, J., and Hungate, B. A.: Responses of terrestrial ecosystems to temperature and precipitation change: a meta-analysis of experimental manipulation, Glob. Change Biol., doi:10.1111/j.1365-2486.2010.02302.x, 2010.

Wullschleger, S. D., Hanson, P. J., and Todd, D. E.: Forest water use and the Influence of precipitation change, in: North American temperate deciduous forest responses to changing precipitation regimes, edited by: Hanson, P. J. and Wullschleger, S. D., Springer, New York, USA, 2003.

$\mathrm{Xu}$, C. G., Liang, C., Wullschleger, S., Wilson, C., and McDowell, N.: Importance of feedback loops between soil inorganic $\mathrm{N}$ and microbial communities in the heterotrophic soil respiration response to global warming, Nat. Rev. Microbiol., 9, 222, doi:10.1038/nrmicro2439-c1, 2011.

Zhang, Y., Moran, M. S., Nearing, M. A., Ponce, C. G. E., et al.: Extreme precipitation patterns and reductions of terrestrial ecosystem production across biomes, J. Geophys. Res.-Biogeosci., 118, 1-10, 2013.

Zhou, L. M., Tucker, C. J., Kaufmann, R. K., Slayback, D., Shabanov, N. V., and Myneni, R. B.: Variations in northern vegetation activity inferred from satellite data of vegetation indexduring 1981 to 1999, J. Geophys. Res., 106, 20069-20083, 2001. 